\title{
EL CULTO AL EXCESO EN LOS INICIOS DEL IMAGINARIO CRIMINAL EN ESPAÑA
}

\author{
Elena DEL Río PARRA \\ Georgia State University \\ rio@gsu.edu
}

mataron tres mercaderes

y $\sin$ haber ocasiones

por sus gustos y placeres

les sacó los corazones.

Francisco Casado

(Obra nuevamente sucedida, 1595)

\begin{abstract}
1 i algo enervaba a Lope de Vega era la invención de sucesos criminales para su venta en pliegos «de hombres que en las ciudades de España fuerzan sus hijas, matan sus madres [...] y afirman que los castigaron en tal parte, donde nunca se vio ni oyó tal cosa» (G. ${ }^{a}$ de Enterría 1973: 89, 2v). Este problema, en cambio, resultaba completamente irrelevante para un público que, si atendemos a la dilatada presencia de material delictivo en multitud de fuentes diversas y alejadas en el tiempo, lo acogía con entusiasmo. Autores como José Pellicer reconocían que los crímenes debían ser entretenidos y, en caso de no producirse, era lícito inventarlos o amplificar algún suceso nimio para convertirlo en llamativo. Conocidos aficionados al crimen - José de Maldonado de Ávila y Saavedra, Pedro Mexía, Diego de Góngora, los jesuitas Sebastián González y Rafael Pereira, Francisco de Ariño, Luis Zapata, José Pellicer, Matías Escudero de Cobeña o Jerónimo de Barrionuevo - , forman un grupo de ávidos correspondientes, cronistas y copistas de sucesos variados que intercambian con entusiasmo lector y transmisor. Sus dos siglos de actividad dan buena prueba de que el entretenimiento sobrepasaba el espectro puramente informativo de una noticia, que se prefería inventada para cobrar vida propia: «De Mérida y Badajoz avisan que había muerto
\end{abstract}


casi de repente el duque de Berganza, estando leyendo una carta, y de este suceso han venido varias de estos dos lugares; mas tiénese por fábula y que ha sido nueva echada allí para que se divulgase por otras partes del reino, como suelen hacer con otras los que tienen ganas de entretenerse» (Cartas V: 441). El interés, moneda que fluctúa según la oferta y la demanda, cobra más valor cuando los sucesos escasean: «Aquí en Bilbao sucedió ayer una desgracia: llevaba consigo de noche un mozo una mozuela; llegose otro a reconocerlos y el que la llevaba, al primer lance le dio al otro tres estocadas, de que está ya espirando. Aquí sucede esto pocas veces, y así es más digno de reparo» (Cartas II: 175). La distinción entre «hecho» y «ficción» es irrelevante para un público para el que la verosimilitud es difícil de calibrar porque no busca lo verdadero sino lo raro. El crimen, considerado ya de por sí una categoría anormal, engloba sucesos más o menos convencionales junto con otros que le granjearon una acepción propia dentro de la voz «exceso» en el Diccionario de la Real Academia: «Demasía, maldad, enormidad, culpa y delito grave» (454).

La información de origen judicial es una fuente que permite un determinado tránsito del ámbito letrado al popular. Los relatos transcritos por el oyente en forma de testimonios jurados pasaban a la Sala del crimen, donde el relator y el notario anotaban y certificaban su veracidad. Esta documentación era presentada en el juicio, donde testigos, abogados, fiscal, juez y otros funcionarios públicos accedía a ella de primera mano, al tiempo que los pregoneros diseminaban la información - crimen, sentencia y condena - en el espacio público. El eclesiástico se hacía ocasionalmente eco de los delitos en forma de condena, a veces exagerando o reinterpretando libremente los hechos y sembrando malas ideas en los feligreses a quienes se pretendía guiar, si hemos de fiarnos del testimonio condenatorio de López de Úbeda (I: 78).

En sentido inverso, la transmisión oral deja con frecuencia su marca en los textos escritos («se me informó», «dicen», etc.), marcando el boca a oído como forma cotidiana de diseminación. La ósmosis de lo escrito a lo oral, de lo letrado a lo iletrado y de lo culto a lo popular, junto con la curiosidad, el escándalo y la naturaleza relativamente efímera de los sucesos, son coordenadas que desembocan en la imposibilidad de llegar a la raíz de unos hechos que, por otra parte, pueden no ser tan interesantes como finalmente se cuentan. Por otro lado, el formato de un informe judicial se conforma de acuerdo con parámetros que dan cabida a unos sucesos criminales para los que no están pensados. Esa misma información, libre de hechuras burocráticas, puede ser aprovechada para reorganizarse metódicamente en formas ya existentes (alegorías, series, segmentos narrativos, arquetipos, fórmulas, etc.), patrones que se asocian a la ficción culta y popular, letrada y oral. Es decir, que las mentiras denunciadas por Lope de Vega cobran verosimilitud mediante recursos artificiales comúnmente empleados para construir ficción 
al tiempo que se presentan como hechos, lo que resulta en una ecuación complicada por la naturaleza de la propia materia criminal: breve, efímera y presente en distintos medios (pliegos, sentencias, cartas misivas y noticieras, avisos y gacetas, alguna crónica), en prosa y verso, en versiones contradictorias, aderezadas, amplificadas o abreviadas. El no poder diferenciar entre realidad y ficción no es un problema del lector sino una incomodidad que concierne al estudioso o a escritores como Lope, quienes ven amenazado su mercado y el bienestar moral de la República. Como prueba el caudal ininterrumpido y omnipresente de crímenes violentos en diversas y variadas fuentes, lo único que quieren los ciudadanos es ser entretenidos, divertidos y alarmados. Prefieren el exceso a la verdad.

\section{Asesinato Al POR MAYOR}

El estudio de sucesos criminales revela la concurrencia a un acervo compartido por escritores, lectores y oyentes partícipes de un género donde los papeles son fácilmente intercambiables, dentro de una cadena de comunicación que alimenta «a genre that has proved to be remarkably resilient in a cultural field dominated by fads and fashions» (Schmid 2010: 198). Fuentes fragmentarias y breves referencias - el ecosistema natural de los sucesos criminales - permiten una representación flexible de hechos supuestos que enfatiza algunos aspectos, al tiempo que excluyen información relevante desde un punto de vista policial o forense.

Esta evidencia, dispersa en varios formatos, lugares comunes, motivos, fórmulas y arquetipos narrativos, produce un resultado sorprendentemente homogéneo que revela un algoritmo activo en un corpus que emplea diferentes sistemas para sustentar datos presentados como nuevos, verdaderos y únicos. A falta de un género propio, estos patrones recurrentes sirven para encapsular un contenido que refleja obsesiones, coartadas, modi operandi y métodos especiales de asesinato y «limpieza». A diferencia de sus contrapartes calvinistas, puritanas y anglicanas, el acervo criminal español evita casi deliberadamente una función religiosa o punitiva, limitándose a constatar las sentencias correspondientes en el código legal sin amplificación moral. Libres de las abrumadoras y prolijas lecciones de sus pares europeos, los relatos se centran en el delito, relegando u omitiendo el sermón y ampliando los segmentos dedicados a la comisión de un asesinato para prestar especial atención a la organización metódica del exceso.

Según Jerónimo de Barrionuevo, los sucesos criminales están inexorablemente atados unos con otros, por lo que presta atención a enfatizar la cadena como una estructura donde las efemérides desastrosas ocurren en sucesión continuada. Concatena, así, sucesos breves para reafirmar que las desgracias nunca vienen solas, 
destacando el efecto acumulativo a través de la yuxtaposición: «Anoche mató un caballero a su amiga. Una mujer se echó en un pozo. A un hombre mataron. Un contador se quedó muerto. Y dos días ha, en Alcalá de Henares, amaneció un regidor fuera del lugar ahorcado en una cruz, con su espada en cinta y broquel al lado. [...] El diablo anda suelto. Ténganos Dios de su mano» (Avisos I: 93). Cuando los eventos de que quiere dejar constancia son algo más extensos, Barrionuevo etiqueta cada uno de ellos con una frase idéntica para dejar una guía y poder entrar en detalles sin renunciar al encadenamiento funesto dando, de paso, la impresión de una simultaneidad que desafía las leyes del azar:

El mismo día sucedieron mil desgracias. En primer lugar, se echó de lo alto de Palacio, desde las barandas de piedra hacia el cuarto del Duque de Medina de las Torres, Doña María de Miranda [...]. Este mismo día mataron cinco hombres desdichadamente [...] con el jifero le atravesó el corazón [...]. Este mismo día hallaron en la Encarnación a la hermana del Marqués de Villamagna, portera, sentada y muerta en la portería con la llave en las manos (Avisos IV: 153-154, énfasis nuestro).

Esta lista, abreviada en favor de la concisión, se amplía con otras noticias fatales sucedidas ese mismo día para probar que las efemérides se organizan en series y montajes no por narrativos menos inevitables. No es casual que casos ocurridos en serie y en masa, cronológicamente dispersos o simultáneos, disfruten de una transmisión preferente entre los sucesos sangrientos. Estos relatos dan cabida a un gran número de eventos vinculados a un mismo autor, dentro de un acontecimiento espectacular por su naturaleza organizadamente fragmentada. Es el caso de Juan de la Daga, panadero próspero cuya codicia derivó en robo, violación y asesinato. El registro criminal exhibido en su Famosa xácara nueva de 1681 incluye el apaleamiento furioso de clérigos, el asesinato de una pareja adinerada y de un oficial de la ley, la fuga de una prisión, el apuñalamiento de una pastora y el tiroteo de un fiscal, formando una secuencia muy familiar para los aficionados al género.

La expresión «economía del exceso» no es un oxímoron sino que hace uso razonable del gasto, devolviendo lo invertido en una forma de asombro y admiración que permite organizar un alto número de eventos. Un texto criminal no es «mejor» por ser simplemente excesivo, sino que debe atender a la variedad y cantidad de sucesos, a un esquema complejo, o a una estudiada desproporción. En ambos casos, los testimonios son producto de un exceso que se alinea con la naturaleza de un lector transversal que prefiere el derroche, a riesgo de ser calificado de «bajo», «primitivo» o «inculto» (no civilizado). La tensión se acrecienta porque la comunidad que genera e intercambia este tipo de sucesos percibe a quienes los comete como «salvajes», situándose moralmente por encima de los hechos, al 
tiempo que los modela y transmite para satisfacer un grado de «salvajismo» enfatizado o, al menos, no atenuado, por el que esa misma comunidad ha sido acusada muchas veces de seguir instintos primitivos, medianamente excusados por la demanda de un público todavía más elemental.

El objetivo de los autores/transmisores es, en todo caso, exhibir un buen asesinato y el éxito depende en gran medida de una economía textual excesiva. Las contradicciones entre la economía y la naturaleza humana clásicamente debatidas por Georges Bataille y Jean Baudrillard, donde el capitalismo contiene la tendencia natural al gasto superfluo, no son un problema cuando los hechos rebasan el segundo factor de la ecuación situándose en un plano estético. El exceso cuantitativo es rastreable en algunas manifestaciones anteriores a la Revolución Industrial, por ejemplo en la serie de bandidos que protagonizan los primeros romances modernos cuyos variados crímenes se amontonan en las coplas y resultan desproporcionados al fin que persiguen ${ }^{1}$.

Los relatos y testimonios de tema criminal, paradójicamente breves, abundan en tramas apoyadas en la multiplicidad, donde los asesinos matan a una serie de víctimas, traman asesinatos complejos o infligen acciones violentas de diversa naturaleza sobre un cuerpo. El «asesinato al por mayor» ${ }^{2}$ se encuentra en impresos de esquemas bastante triviales como la Relación cierta y verdadera del más estupendo y espantoso caso que se ha oido. Refiere el estrago a manos de un hombre quien, después de dejar el clero para casarse, en su noche de bodas asesinó a su esposa, a su suegra, a un niño y a dos parientes. Bajo un arquetipo narrativo similar («mujer que asesina al marido para estar con su amante»), la Verissima relacion que Francisco Pérez publicó en 1606 destaca por presentar una estructura lineal completa y equilibrada compuesta de motivación, plan, cómplice, ejecución, acusación injusta, detención y ajusticiamiento. Los celos se apoderaron de una mujer casada, enamorada de un joven cirujano que cortejaba a una dama de su edad, enfatizando cuán obsesionada estaba la dueña («no reposa ni sosiega»),

1 La industrialización acompañará la proliferación de este esquema, cuyo récord se encuentra en el pliego inaugural, impreso por Andrés de Sotos y reproducido durante más de cien años, acerca de las matanzas de la banda formada por Andrés Vázquez y sus seis hermanos (De Andrés Vázquez, y sus hermanos). De un total de doscientos setenta y dos versos, ciento setenta y ocho se dedican a presentar veinticuatro acciones violentas, a dos versos por crimen, reservando únicamente veinticuatro a la introducción y sesenta a la persecución y ajusticiamiento de los «siete hermanos bandoleros». Su representación gráfica oscila entre tres y seis malhechores en impresos más tardíos.

2 Al tiempo que el negocio de la prensa de masas llenaba de problemas el imaginario estadounidense, autores como Ambrose Bierce (1842-¿1914?) y Edmund Pearson (1880-1937) empezaron a referirse a las «condiciones del mercado del crimen» (crime market), a una masacre como un «trabajo» (job) y a la matanza en serie como «asesinato al por mayor» o «a granel» (wholesale murder), amoldando la terminología capitalista clásica a las narraciones criminales. 
hasta el punto de encontrar una cómplice que asesinase a su esposo para casarse con el médico. La coautora, sin ninguna justificación, resultó estar más motivada que la propia instigadora e ideó un plan para envenenar al marido, diciendo a los vecinos que había regresado muy enfermo del trabajo. Finalmente la esposa lo remató apuñalándolo con una aguja de tapicero impregnada en helleborus foetidus («yerva, / que dicen del ballestero»). Una vez ejecutado y enterrado, la ya viuda propuso matrimonio al cirujano para completar su plan maestro pero, al ser rechazada, volvió a involucrar a su cómplice en el estrangulamiento de la dama pretendida para eliminar el segundo obstáculo. Después de matar a su rival, junto con su madre y una sirviente testigo del asesinato, la justicia finalmente logró obtener una confesión, y tanto la asesina como su cómplice fueron ahorcadas en la escena del crimen.

Antecedentes similares aparecen en la Obra nuevamente sucedida de Francisco Casado (G. a de Enterría 1974: 145-152), que detalla cómo una mujer mató a sus cuatro hijos y arrojó sus cuerpos a un aljibe estratégicamente ubicado justo debajo de la ventana de la habitación donde había cometido el crimen. En este caso es la mujer quien sirve como ejecutor instrumental de un parricidio masivo. Convencida por su amante, un arriero, de que tenía que matar a sus cinco hijos para estar juntos, la instruye detalladamente sobre la forma más efectiva de llevar a cabo los asesinatos, incluido el momento, el arma y una forma factible de deshacerse de los cuerpos:

aquesta noche será / a la hora de las tres. / Y a tu hija Catalina, / y Ana y también Leonor / matarás, y a Salvador / porque salga de mohína / y esto será lo mejor. / Tomarás esta navaja / con que puedas degollarlos / y a tu seguro matarlos / y por la ventana abaja / puedes en el pozo echarlos / [...] / Y con sus escapularios / los echó dentro de un pozo / con unos intentos varios / haciendo tanto destrozo / como si fueran contrarios / [...] / Todos atemorizados / hacia el pozo se allegaron / donde fueron sacados / y todos cinco hallaron / bien blancos y colorados.

En los tres días que tardaron en encontrar los cadáveres la pareja había tenido tiempo de huir y, uniéndose a un escuadrón de quince bandidos, robar a lo largo del camino real, obligar a bailar a algunos frailes desnudos para humillarlos, y masacrar a tres mercaderes sin motivo alguno. La obra de Casado es un buen ejemplo de subgénero cruzado, abundante en coplas que comienzan como un asesinato masivo, en este caso por delegación, y derivan en un romance de bandidaje, disección incluida, que se remata con un toque milagroso.

Esta clase de cruces es frecuente en textos donde un criminal idea un sistema para poder matar de forma continuada, pasando desapercibido durante mucho tiempo. Las manifestaciones más antiguas se sitúan en pasos de montaña obligados donde el aislamiento sirve de tapadera a serranas caníbales, pero se 
encuentran también en despoblados, caminos y enclaves urbanos. Independientemente de su localización y a juzgar por el número de textos existentes, el asesinato en serie resulta atractivo, especialmente cuando la matanza se dilata durante mucho tiempo. La simulación encuentra un escenario ideal en las coplas donde se usa una actividad comercial como excusa. Algunas cartas privadas aluden a bandidos que pertenecen a diferentes extracciones sociales y diversifican sus actividades, bien como asesinos a sueldo, bien como confesores de bandas organizadas ${ }^{3}$, mientras que en varias coplas anunciadas como de salteadores un comercio sirve para proteger actividades mortales que pasan desapercibidas. La Famosa xacara de Alonso de Mena detalla sus crímenes en primera persona, enfatizando el taimado modus operandi aprendido en sus orígenes como chatarrero, actividad asociada a maleantes, para establecerse más tarde como joyero y vidriero. Cortado del mismo paño que Juan de la Daga, quien regentó «negocios» desde su próspera panadería para luego establecer una casa del crimen cerca de un camino apartado, Alonso de Mena es el epítome de un criminal de carrera ascendente que usó su joyería y cristalería como lugar de operaciones desde el cual vendía el producto de sus robos ${ }^{4}$. Estas versiones híbridas conservan el formato gráfico de los salteadores rurales típicos del siglo anterior, pero el grueso del texto se corresponde a bandidos fugados de prisión que emprenden una variedad de oficios como cubierta de una actividad criminal que exige el asesinato en serie para funcionar, sin llegar realmente a «trabajar» en las carreteras como sus predecesores, haciendo de la muerte su principal objetivo.

Tal vez fue Teresa Delgado quien diseñó el mejor esquema de cuantos han quedado consignados, sistema que le permitió continuar asesinando durante varios años. Mientras que para Fink De Backer este caso personifica la dura vida de

3 Una carta en el Memorial histórico español se refiere a la subcontrata de bandidos rurales para llevar a cabo «trabajos» urbanos de saldo: «Estos días pasados cogieron aquí dos bandoleros valencianos por aviso secreto que la justicia tuvo. Su venida, dicen, era a matar alguna persona de cuenta que no se ha podido averiguar [...] Muertes hubo que cometió por dos reales y medio: tan baratas las hacía» (Cartas VI: 350). Otra misiva apunta a la subdivisión laboral dentro de una misma banda, uno de cuyos miembros confesaba a las víctimas antes de despellejarlas: «Ayer tarde entraron en esta Corte 50 migueletes o bandoleros con un fraile franciscano y un clérigo, y luego los llevaron a la cárcel de Corte, porque a cuantos castellanos cogían el fraile los confesaba y ellos los desollaban; no sé lo que harán de ellos» (Cartas VI: 36).

4 Manuel Alvar señala que, si bien los pliegos de crímenes escasean durante el siglo XVIII, proliferan los de salteadores. Curiosamente, la colección Casas y Martínez editada por el mismo Alvar incluye, disimulados bajo la etiqueta de «bandidos», esquemas misceláneos que no corresponden a latrocinios semi-nómadas o de camino sino a otros sistemas de matar. Junto a los romances convencionales de Felipe Centellas, un ladrón que terminó sirviendo al rey, figura el de Francisco Pomares, criminal nato y asesino en serie; el de Francisco Correa, quien comenzó su carrera pegándole a su maestro y cometió asesinatos múltiples; o el de Agustín Florencio, quien asumió la tarea de liberar convictos y cuya especialidad consistía en abrir «una ventana en el cráneo». 
una viuda responsable de mantener a su familia ${ }^{5}$, desde la perspectiva de la tradición criminal los detalles del suceso indican un patrón conocido. Delgado enviudó al matar a su esposo, después de lo cual cometió una serie de asesinatos, se deshizo de los cuerpos enterrándolos dentro de su casa y construyó coartadas que no se detectaron. A diferencia de muchas otras viudas en la sociedad castellana, las necesidades financieras no estaban relacionadas con su motivación. Muy al contrario, el asesinato del proveedor de la familia desencadenó una historia arquetípica y similar a otros crímenes en serie encubiertos, ahora recurrentes como subgénero pero escasos en el siglo xvI, hecho que Sebastián de Horozco aprovechó para colocarla junto con otros casos singulares en su «Memoria y relación de un caso extraño» (lluvia de sangre, el avistamiento de tres soles o tres lunas, el matrimonio entre dos hombres, un terremoto). Tras alojar a los viajeros en su casa, Teresa Delgado solo tenía que repetir la misma historia cuando los huéspedes desaparecían, siendo la escenificación incorrecta de un ahogamiento la causa final de su detención. El bachiller Navarro, cronista directo del suceso, expresó su incapacidad de comprender aquello que estaba refiriendo, haciéndose eco de la opinión de los vecinos, desconocedores de este «estraño caso»: «lo que a todos espanta es la crueldad de esta mujer [...] por espacio de cinco o seis años matar siete personas y enterrarlas dentro de su casa y dormir sobre ellos y entre ellos su marido, comer en la cocina sobre los otros, $[\ldots]$ y no turbarse después de matallos $[\ldots]$; yo creo que a v. m. y a todo el mundo parecerá cosa de admiración» (64).

Jerónimo de Barrionuevo quedó igualmente asombrado cuando supo de los cuarenta y siete asesinatos que había cometido en Madrid una envenenadora aragonesa infiltrada en varias casas. La sirviente intentó matar durante el mayor tiempo posible, dosificando el tósigo en grado proporcional al patrimonio de su víctima. Ocupaba un puesto permanente en la casa del conde de Santisteban, entremezclándose con los miembros del personal en las cocinas de otras casas para envenenar los guisos antes de servirlos, tras lo cual se quedaba para cuidar al enfermo mientras cometía pequeños hurtos, aunque Barrionuevo declara en sus tres cartas que mataba por placer y por vicio, y que el mismo infierno debería huir de ella por «enemiga del género humano» (Avisos I: 104), aceptando precavidamente lo inexorable. Su rudimentario método y sobradas pruebas condujeron a una rápida aprehensión de la mujer, quien a sus cincuenta años aguantó seis horas de tortura sin pestañear mientras aleccionaba a su verdugo.

Matías Escudero de Cobeña, por su parte, dejó consignado el sofisticado caso de Pedro Rezena, infiltrado en el sistema legal para actuar como salteador de caminos y juez de sus propios sumarios. Este «extraño caso notable», fechado en

5 «Aside from the bizarre particulars of her homicides, the story that unfolds reveals details of Teresa Delgado's life that parallel the position of many widows in Castilian society» (291). 
1592, se registró sin escatimar en detalles sobre la crueldad de este ladrón, que se hizo con una vara de justicia. Después de cortarle la lengua a su propio padre y clavarla de un árbol, terminó fabricando escenarios criminales para facilitar su propia labor judicial: «Y como este traidor la vido en el suelo, tal y traspuesta, cumplió con ella su voluntad, sin ella sentillo. Y como así la vido, echole un cordel al cuello y colgó a la mujer de una viga, y él atrancó la casa, y desquició una puerta secreta, y se salió de la casa y se fue a su casa» (280-282). Al igual que Teresa Delgado, Rezena fabricó una falsa escena del crimen que simulaba un suicidio o un accidente, cabo del que tiraron las autoridades para descubrir sus sistemas de matar.

\section{Cifras y letras}

Los cruces narrativos, frecuentes en un género en formación, son también inherentes al folklore, que circula, como la propia materia criminal, entre lo iletrado y los ámbitos más intelectuales. No sorprende, por tanto, el aprovechamiento de motivos folklóricos y arquetipos narrativos en textos firmados. Quienes estén familiarizados con la teratología reconocerán la difundida leyenda de Margarita de Irlanda u Holanda en la Relación muy verdadera de Fernando Álvarez. Relata la conocida maldición sobre una mujer noble que dio a luz a trescientos setenta hijos tras acusar a una indigente de promiscuidad porque tenía una familia numerosa. Este texto, recurrente en relatos sobre nacimientos múltiples, no suele centrarse en el castigo moral sino en el tamaño y condición de los recién nacidos, extendiéndose hasta bien entrado el siglo XIX como «los cinco hijos de un parto». La leyenda ancestral se convierte en una notable historia criminal en la versión que Diego Gasque redacta en el siglo XVI (G. ${ }^{a}$ de Enterría 1974: 161-167). Su Caso espantoso la refunde con el cuento del origen de los Welfos, menos conocido en fuentes hispánicas ${ }^{6}$, aprovechando dos líneas arquetípicas: el castigo a través de un parto múltiple y su posterior desarrollo como infanticidio masivo.

Construido bajo un patrón numérico, el texto comienza presentando a la habitual pordiosera mendigando acompañada por sus mellizos en la casa de una dueña adinerada quien, recurriendo a la creencia popular, la acusa de promiscuidad al creer que cada niño es de un padre diferente. Tras ser maldecida por la indigente, la historia se transforma completamente, hilvanando un sangriento tejido ausente en las versiones clásicas de Margarita. La dueña envió a una esclava para actuar

$6 \quad$ Si consideramos que Diego Gasque fue procurador en la villa de Villena, podría haber tenido acceso al Fructus sanctorum de Alonso de Villegas (1594), en cuyo quincuagésimo primer discurso se encuentran ambos relatos consecutivamente («De milagros», §34 y $\$ 35$ ). Al tratar ambos de partos múltiples no resulta muy complicado amalgamarlos ampliando el número de personajes. 
como asesina a sueldo y vengarse de la pordiosera, tras lo cual ella misma asesinó a los mellizos y los enterró en una cueva dentro de la casa ${ }^{7}$. Tras dar a luz a siete niños como resultado del maleficio, la rica dama se vio abocada a sobornar a su esclava y a su partera para que ahogaran a seis de las criaturas con el fin de no ser acusada de adulterio por su marido. De camino hacia el río, la esclava se encontró con el esposo, quien la apuñaló seis veces y hundió el cuerpo atándolo a una piedra, se llevó a los seis hijos y contrató a seis nodrizas. ${ }^{8}$. Siete años más tarde anunció que iba a invitar a seis extranjeros a casa y les preparó una exquisita comida donde desveló la trama9 .

Dependiente de una estructura numérica tradicional, Gasque hace recalar una conocida leyenda en un crimen masivo, agregando un fuerte aspecto teatral a su desenlace: la concurrencia de los «invitados» a la mesa y el doble papel de la esposa como juez y acusada se apoya en la metaficción de una manera inesperada. Comúnmente los textos criminales suelen resaltar el «arte» del asesino, quien muestra la capacidad de concebir y ejecutar acciones violentas y extremadamente sangrientas en el cuerpo humano, yendo más allá de una simple lectura simbólica para deambular por la estética de una muerte excesiva. Autores y lectores saben que una narración criminal destaca, por ejemplo, mediante amplificaciones en la coartada, el ocultamiento de un arma, un medio inusual de ejecución o un método original para deshacerse de un cadáver que da vía libre a la impunidad. Textos como el Caso espantoso son la punta de un iceberg en una miríada de relatos que hacen uso de la simulación, ubicando el acto criminal en el centro de un escenario más elaborado y complejo que, en este caso, pone las cifras asociadas al folklore al servicio de la criminalidad.

La abundancia, categoría cuantitativa y lineal por definición, no da cuenta de construcciones en las que un solo evento agranda sistemáticamente detalles

«y la esclava arremetió / con un ímpitu muy fuerte / con un cuchillo le dio / por la ijada de tal suerte / con que la pobre acabó. / Y como muerta la vio / con unas entrañas crudas / la dama se levantó / con sus manos degolló / las chicas dos cri[ä]turas. / Hecha ya la desventura / encendida en viva brasa / en una gran cueva escura / que había dentro de casa / les dieron la sepultura».

8 En el segundo argumento se identifican variantes de motivos catalogados por Stith Thompson: «Niño expósito criado en secreto»; «madre cruel mata a su hijo», y «niño no deseado, expuesto; niño deseado, conservado» (S350.2, S12.2 y S311).

$9 \quad$ El pliego concluye con una sentencia habitual: la esposa queda impune y la partera recibe cuatrocientos latigazos y es encubada. El encubamiento (lat., culleus) es una sentencia frecuente en diversos textos, aunque no se detalla si el código legal se seguía al pie de la letra puesto que exigía una víbora, un mono, un gallo y un perro para acompañar al sentenciado en su periplo fluvial (Covarrubias, voces «víbora» y «cuba»). La mayoría de las referencias apuntan a la ejecución del culpable antes de ser encubado, sin inclusión animal, para ser recuperado posteriormente por su familia o una cofradía religiosa, tras lo cual se procedía a purificar el agua del río. 
minúsculos. En cambio, como parte de la economía del relato excesivo, el esfuerzo invertido en la desproporción, en lo inútil y en lo absolutamente innecesario resulta en un crimen ineficiente pero en un imaginario más poderoso, producto de un exceso cualitativo tan problemático como productivo. Los motivos, tropos dinámicos de forma variable, resultan ideales para expresar el «exceso de muerte» en algunas fuentes impresas. Cuando Barrionuevo relataba el intento de asesinato de don Juan de los Herreros se aseguró de especificar el número de puñaladas (catorce), indicativas de un alto grado de violencia que además apuntan a una recurrencia cifrada ${ }^{10}$. La cuenta suele incluirse en coplas como la Relación verdadera de Francisco Soto, donde el sastre Juan de la Parra tijereteó a su mujer por celos («le dio tres fuertes heridas / que estas el cuerpo le pasan»). Una mujer que viajaba a Perpiñán apuñaló también tres veces a un soldado que la atacón ${ }^{11}$, y un vecino de Villa de Cebolla se ensañó con su padre apuñalándolo tres veces antes de cerrar puertas y ventanas, indicio de que planeaba acrecentar la carnicería: «Le dio cuatro puñaladas / con tal rigor y violencia, / que era la una bastante / para excusarse las penas. / Despertó casi difunto: / diciendo con voces tiernas, / María, y ella callando, / cerró ventanas y puertas. / Por tres veces la llamó, / y por que presto muriera, / pasó de uno a otro oído / una almarada perversa» (Cvriosa xacara). Evidentemente, una puñalada certera mata igual que catorce, pero una cifra desproporcionada logra no solo asesinar, sino también incorporar efectos rituales y sentimentales en textos que toman prestados recursos externos para cimentar un género en formación. La efectividad intelectual del arma del crimen es detectable en obras relativamente tempranas, que consideran cómo muchas armas matan pero no todas lo hacen de la misma forma. Las particularidades de la almarada, por ejemplo, le granjearon el mote de «chupasangre» por infligir un tipo muy particular de herida con escaso daño visible y una hemorragia interna letal, de ahí sus atractivas cualidades para realzar impresos como la Cvriosa xacara.

10 El número de puñaladas, significante de «heridas mortales», generalmente entre dos y cuatro, es muy familiar para los oyentes de romances viejos, incrementándose hasta unas veinte como claro signo en crímenes pasionales como el de Herreros y otros individuos obcecados. La cuenta no solo refleja animadversión sino que, en casos como el de Julio César, el alto número de conspiradores que infligieron las veintitrés heridas. El doble uso continúa hasta el siglo XIX en textos como el Romance admirable en el cual se refiere la crueldad de la mas ingrata muger para con un hijo suyo de cinco años, el que degolló, sacó los ojos y el corazon de tres puñaladas: dentro de un crimen singular, la laceración del cuerpo se presenta como una serie (degollación, extracción de los globos oculares, más un triple apuñalamiento cardíaco).

11 «Salió una mujer de Salsas para Perpiñán, y en el camino encontró con un soldado de a caballo que la quiso forzar. Ella, lidiando con él, le sacó el puñal del cinto y le dio con él tres heridas, de las cuales cayó muerto; quitole las armas y púsoselas, y subiendo en el caballo se encaminó a Perpiñán» (Cartas II: 293). 


\section{El culto al exceso}

La representación visual de un crimen no solo añade contenido a disposición de los lectores, sino que resalta el potencial icónico de unos criminales que exhiben sus «herramientas de trabajo». Los asesinos en acción y las escenas del crimen hacen aparición incipiente en pliegos sueltos de mediados del siglo XVIII, si bien los avances xilográficos no se aplicaron a las impresiones de menor calidad hasta el xIx. Como ya habían explotado la hagiografía y el martirologio, proyectan una especie de perspectiva trágica donde las víctimas, conscientes, no pueden escapar de su destino fatal. Por ejemplo, la «Lucrecia de Nieves» compuesta por Andrés de Sotos a mitad del siglo XVIII exhibe con orgullo un par de enormes tijeras como arma característica, gesto que iconográficamente se aprovecharía un siglo después en la configuración de Francisquillo «el Sastre» para resaltar el mismo utensilio. Estos grabados demuestran hasta qué punto una Ilustración proporcionada y ponderada - que pretendía contrarrestar un Barroco excesivo y obsceno- no fue más que la construcción de una generación cultural que, aunque se consideraba «iluminada, tendía a glorificar a los asesinos y colocarlos en escaparates hechos a medida del exceso» ${ }^{12}$.

Junto con la incorporación de toques científicos, los impresores decimonónicos se interesaron cada vez más por la representación gráfica del cuerpo desmembrado. Imágenes que solían ser exclusivas de ciertos libros de cirugía se convirtieron en encabezamiento habitual en pliegos sueltos, como encabezamiento atractivo para los aficionados al género criminal. El aspecto visual de la criminografía mejoró al mostrar laceraciones gráficas en el cuerpo, un número creciente de descuartizamientos, cabezas amontonadas, chorros de sangre y salpicaduras. Sorprendentemente, las estructuras narrativas clásicas también se explotaron visualmente: los triángulos de amor, comunes en la novela renacentista y la escena áurea, se representan ahora como asesinatos dobles y triples, englobados como actos de simultaneidad distintivos, bien por el regreso del clásico esquema de homicidio-suicidio, bien dentro de un crimen adecuadamente sincronizado. Aun así, la representación gráfica de una escena, aunque impactante, es incapaz de captar la experiencia temporal cuando se trata de decodificar el asesinato como una progresión regulada. El lector debe conformarse con la singularidad del efecto chocante en la ilustración y esperar a la secuencia criminal que solo el texto escrito puede proporcionar.

El acto de matar sufre cambios fundamentales durante la Revolución Industrial, exhibiendo un esfuerzo sistemático por acentuar la abundancia a través de

\footnotetext{
12 Campomanes y Meléndez Valdés, entre otros intelectuales, advirtieron de que los tintes moralizantes de dichos textos se veían ampliamente sobrepasados por la obscenidad de las acciones representadas (Bolufer y Gomis 2011: 226-227).
} 
textos más extensos, versiones más difundidas geográficamente, grabados más grandes y series más largas de asesinatos, que comienzan a dividirse en partes para su venta por separado. El exceso, cualitativamente hablando, se cultiva en formas como asesinatos organizados según un desplazamiento geográfico, anteriormente escaso fuera del bandolerismo, que se extendió como estructura común en los romances post-industriales protagonizados por mujeres. Al igual que el «parricidio por el cabeza de familia» se convirtió en un motivo cada vez más común en las letras inglesas a finales del siglo XVIII (Halttunnen 1998: 139), las fuentes españolas oficializarán el estado de la mujer como el más cruel de los seres según lo predicho por Jerónimo de Barrionuevo, convirtiéndolo en un cliché. Los «asesinos-estrella», seres vengativos que actúan por puro impulso irracional más allá de las limitaciones sociales para matar a un gran número de víctimas y perpetuar el ensamblaje, nacerán ahora bajo la enseña de Lucrecia de Nieves, Teresa de Llanos, Sebastiana del Castillo, Isabel Gallardo y Espinela ${ }^{13}$. Asimismo, la mayoría de los lectores recordarán la clásica leyenda del siglo XVII sobre pasteleros que, en tiempos de escasez, utilizaban carne procedente de los cadáveres de los ajusticiados. El asunto se retoma a mediados del siglo XIX en el Nuevo y lastimoso romance de Julián Ripoll, y se extiende a casos de infanticidio y canibalismo como el de Juan Esteban de Argalia, afianzando el poder cultural de los mantequilleros y las parteras abortistas que evisceran con entusiasmo a sus víctimas, beben su sangre, extraen su grasa y alimentan a sus animales con restos de cadáveres. Estos prolíficos arquetipos y variantes de asesinos en masa y en serie prefigurados en la modernidad temprana aprovechan los mimbres sobre los que agregan una mayor «cantidad de muerte», convertida en mercancía cuantificable.

Desde mediados del siglo XVIII se entiende que «más es mejor»: la criminografía retoca el exceso y lo expande cualitativamente. La disección del cadáver, antes limitada en términos prácticos a destruirlo para no dejar pruebas, presenta ahora nuevos matices, explorando el contenido del cuerpo, la textura y el procesamiento de los diferentes miembros. Esta actividad, más metódica, exige una estructura que envuelva la secuencia criminal — por ejemplo, una receta que organice el despedazamiento y desaparición de un cadáver- y un espacio privado, generalmente una cocina. Fue allí donde Ana María Contreras seccionó la úvula de su esposo en 1749, mientras dormía. Cual hábil carnicera, procedió a destriparlo en el curso de una noche, dejando a un lado el hígado y las entrañas, colgando de

13 Este último es un caso inusual: el pliego, datado en 1841, narra su escapada geográfica convencional, pero Joaquín Marco sitúa la primera versión conocida en Barcelona (1599), en un impreso alojado en la Biblioteca Real Neerlandesa (473). El pliego no figura en el catálogo, por lo que el intervalo «vacío» de doscientos cuarenta y dos años hace sospechar que Espinela se origina, como sus compañeras, en el siglo XIX. 
un clavo el corazón, cortándole la cara, decapitándolo y seccionándole los brazos y, una vez destruido el resto del cuerpo con un par de herramientas adecuadas, macerándolo en ajo y vinagre junto con los cadáveres de sus hijos para dar tiempo a ser enterrados.

Siguiendo la receta, Contreras reservó, picó y sirvió el hígado frito y las tripas a su ingenuo amante, por lo demás un motivo antiguo que se remonta a la mejor tradición española de las serranas:

con un cuchillo en las manos / fue donde está su marido, / y el galillo le ha cortado. / [...] / pues con el mismo cuchillo, / le abrió de arriba hasta abajo / la barriga, y el mondongo / con las tripas le ha sacado, / y las echó en un lebrillo / que tenía puesto al lado; / el hígado y la asadura, / y el corazón le ha cortado, / recogiéndolo en un cesto / y en un clavo lo ha colgado. / Luego con gran ligereza, / fue, y trajo un hacha de manos, / y la cara y la cabeza, / las hizo muchos pedazos, / como si no hiciera nada; / también le cortó los brazos, / con que a su pobre marido / todo lo fue destrozando, / y en dos lebrillos muy grandes / las carnes le fue salando / [...] / y así como fue de día, / fue a la cocina volando, / y encendió una grande hoguera, / y una sartén alcanzando, / el hígado y la asadura / lo hizo muchos pedazos, / con que armó una gran fritada / [...] / Pues tres días y tres noches, / los tres difuntos salados / tuvieron bajo su cama, / sin ser de nadie notados.

La carnicería se organiza mediante una gradación metódica en la que se van extrayendo y despiezando los órganos mediante utensilios especializados, separando los diversos tipos de carne para diversos fines: mientras que el corazón se exhibe aparte, como imagen dominante en la escena, las partes más suculentas se reservan para su consumo, aunando un ritual de venganza con una manera práctica de deshacerse de los restos. El descarte de un cadáver, cuestión puramente práctica en la mayoría de textos anteriores al siglo XVIII, se convierte en una parte fundamental de la construcción poética. La criminología industrial incluye la vivisección pero, lo que es más importante, el procesamiento post mortem que se recrea en explicar las laceraciones corporales y la calidad fluida o gelatinosa de las distintas partes. La cisión de cadáveres ahora tiene en cuenta no solo la mecánica del desmembramiento bruto de sus extremidades, sino también el picado, la cocción, la fritura y el almacenamiento de todas las piezas de una cadena de producción siniestra, lo que explica la proliferación de textos sobre asesinos en serie capaces de perfeccionar sistemas de este tipo, más ventajosos que los negocios-tapadera característicos de la modernidad temprana. Al compás de los nuevos descubrimientos, la química se incorporará también como elemento-clave para la difusión del arquetipo de la envenenadora prefigurado por Barrionuevo — para fabricar en masa la muerte sin esfuerzo - donde encaja como una segunda naturaleza. 


\section{BIBLIOGRAFÍA}

Alvar López, Manuel (1974). Romances en pliegos de cordel (siglo XVIII). Málaga: Delegación de Cultura, Excmo. Ayuntamiento de Málaga.

Álvarez, Fernando (1633). Relación muy verdadera, en que se da cuenta de una mujer natural de Sevilla, que en tiempo de doce años que ha que es casada ha parido cincuenta y dos hijos, y hoy en día está viva. Cuéntase de una señora muy principal de Irlanda, que parió trescientos y setenta hijos en una fuente de plata, y los bautizaron, y esta fuente se la enseñaron al Emperador Carlos quinto, por caso prodigioso. Lleva al cabo una enigma muy curiosa, y un romance nuevo de los mejores que hasta ahora han salido. Madrid / Sevilla: Herederos de Diego Flamenco / Manuel de Sande.

Anónimo (1671). Cvriosa xacara nveva de vn caso lastimoso sucedido en la Villa de Cebolla, y fue que vna donçella le diò la muerte su Padre alevosamente. Refierense los lances que después de muerto passaron, rara crueldad y el castigo riguroso que se hizo en ella Miercoles tres de Iunio deste año de 1671. [s.1.]: [s.e.].

ANónimo (1672). Relación cierta y verdadera del más estupendo y espantoso caso que se ha oido, sucedido en la Ciudad de Cordova por Iunio deste presente año de 1672. Hazese relacion de vn desalmado hombre, que en vna noche de casado degollo a su muger a su suegra, vna niña, y dos parientas de su esposa. Córdoba: Herederos de Salvador de Cea.

Anónimo (¿1681?). Famosa xácara nueva, que hace relación de la vida, y sangrientos delitos, prisión y muerte de Juan de la Daga, salteador de caminos, que ajusticiaron en esta Corte el viernes 16 de mayo deste presente año de 1681. [s.1.]: [s.e.].

Anónimo (¿1687?). Famosa xacara, en que se da cuenta de la prision, delitos, y muertes de Alonso de Mena, que fue castigado en esta Corte a 17 de Março deste año de 1687, y se declaran muchos robos que hizo en Madrid, [...] y cómo estuvo en Presidio [...] y al fin murió ahorcado. [s.1.]: [s.e.].

ANónimo (1749). Nueva relacion donde se da cuenta y declara como una muger llamada Ana Contreras, inducida del demonio, dió muerte á su marido y á dos hijos, y los echó en adobo; y como le dió al galán á comer del hígado, y la assadura frita: refiere, como fueron descubiertos, y ajusticiados el día 27 de julio de este presente año de 1749. Barcelona: Pedro Escuder.

Anónimo (s. XVIII). De Andrés Vázquez, y sus hermanos. Nuevo, y curioso romance, donde se da cuenta de la vida, prision y muerte de siete hermanos vandoleros, y en que se refieren las grandes crueldades, insultos, muertes, y robos que hizo Andres Vázquez, y sus hermanos, como lo verá el curioso lector: los nombres de cada uno son Manuel, Juan, Francisco, Pedro, Gerónimo y Antonio Vazquez, castigados en Ciudad Real. Sucedió en este presente año. Madrid: Andrés de Sotos. 
ANÓNIMO (s. XVIII). Nueva relacion, y curioso romance en que se declaran las muertes que hizo una hermosa doncella, llamada doña Lucrecia de Nieves, por rescatar su honra y como anduvo perdida quatro años por buscar a su amante. Madrid: Andrés de Sotos.

Anónimo (s. XVIII). Primera parte de Don Juan Estevan de Argalia: Nuevo romance en que se declara como este caballero se enamoró de una dama, en quien tuvo dos hijos, dandoles muerte recien nacidos entre él y la dama, bebiendose la sangre $y$ dandosela tambien à un perro, y despues los arrojó á un rio: Declarase como tambien dió muerte à la dama y se enamoró de una señora principal la qual no pudiendo gozarla se valió de una esclava, ofreciendole cien escudos, como lo ocultara en la sala de dicha señora: y como habiendose quedado oculto entre unos paños de Corte, la dió siete puñaladas, sacandola el corazon: con otras muchas que se verán en estos dos romances. Madrid: Andrés de Sotos.

ANónimo (ca. 1844-1874). Los cinco hijos de un parto: Verdadera y estraña relacion del maravilloso parto de cinco hijos varones, que ha dado á luz una muger llamada Maria Gutierrez, natural del pueblo de Jalapa, casada con Isidro Lopez. Declarase la señal con que nació cada uno. El primero con una espiga de trigo en la mano, el segundo con otra de cebada, el tercero con dos espadas en cruz sobre el vientre, el cuarto con un racimo de uvas en la mano derecha, y el quinto con una vara también en la mano derecha. Córdoba: Fausto García Tena.

ANónimo (1857). Nuevo y lastimoso romance por el que se da cuenta del caso más horroroso é inhumano y astucia de Julián Ripoll, el cual tenia un gran figon donde se encontraba de toda clase de comidas, quitando á los demas figoneros la venta por lo bien que él guisaba: su gusto consistia en despachar ternera, asi llamaba á la carne de los inocentes niños que iban á pedir a su puerta y, engañados por él los encerraba y degollaba en la bodega, hasta que la Virgen Santísima hizo fuese descubierta tan grande infamia y castigados el Julián y su mujer como cómplices, en el pueblo de Esparraguera a seis leguas de Barcelona, el dia 25 de julio de 1857. Logroño: Ciriaco Verdejo.

ANónimo (s. XIX). Nueva relacion de los desafios, hazañas y valentias del mas jaque de los hombres, Francisquillo «el Sastre». Madrid: J. M. Marés y Cía.

ANóNImo (s. XIX). Romance admirable en el cual se refiere la crueldad de la mas ingrata muger para con un hijo suyo de cinco años, el que degolló, sacó los ojos y el corazon de tres puñaladas: $y$ del modo que fue descubierta esta causa y su desgraciado fin: como tambien el portentoso milagro de María Santísima del Carmen, con el caballero que la solicitaba, como lo verá el curioso lector. Valencia: Laborda.

Barrionuevo, Jerónimo de (1892-1893). Avisos. Antonio Paz y Melia (ed.). Madrid: Imprenta y fundición de M. Tello, $4 \mathrm{t}$.

Bolufer, Mónica y Juan Gomis (2011). «Delitos "privados” y literatura popular en los orígenes de la opinion pública: A propósito del crimen de Castillo». Estudis, 37, pp. 217-233. 
CASADO, Francisco (1595). Obra nuevamente sucedida en el castillo de Salças en el reyno de Cataluña. La qual trata de un maravilloso milagro que obró nuestra señora del Carmen. Trata de cómo una mesonera dio la muerte a su marido y a quatro hijos suyos por yrse con un hariero, y de cómo el demonio tomó su figura y los echó dentro en un pozo con sus escapularios, y de cómo se vistió en traje de varón y se juntó con quinze vandoleros, y mataron a tres mercaderes de Valencia y a dos frayles de san Francisco, y por ciertas visiones que vido se uino a presentar a la justicia, y cómo fue sentenciada a ahorcar, y estuvo colgada desde las tres de la tarde hasta otro día a las nueve sin morir, y mirándola la justicia le hallaron el escapulario, y quitándoselo murió. Cuenca: Bernaldo de Salvatierra.

Covarrubias Orozco, Sebastián de (1611 y 1674). Tesoro de la lengua castellana o española. Madrid: Luis Sánchez / Melchor Sánchez.

Escudero de CobeÑa, Matías (1982). Relación de casos notables ocurridos en la Alcarria y otros lugares en el siglo XVI. Francisco Fernández Izquierdo (ed.). Guadalajara: Ayuntamiento de Almonacid de Zorita.

FInk De BACKer, Stephanie (2010). Widowhood in Early Modern Spain: Protectors, Proprietors, and Patrons. Leiden: Brill.

García de Enterría, M. ${ }^{a}$ Cruz (1973). Sociedad y poesía de cordel en el Barroco. Madrid: Taurus.

García de Enterría, M. ${ }^{a}$ Cruz (1974). Pliegos poéticos españoles de la Biblioteca Universitaria de Gotinga: edición en facsímile. Madrid: Colección Joyas Bibliográficas, t. 2.

Gasque, Diego [s.a.]. Caso espantoso sucedido en el reino de Navarra en la cudad de Pamplona a una mujer la cual decía que la mujer que paría dos criaturas que era la una del marido y la otra de su amigo, y cómo por voluntad de Dios vino a parir siete criaturas juntamente con las grandes traiciones que hizo [...]. [s.l.]: [s.e.].

Halttunen, Karen (1998). Murder Most Foul. The Killer and the American Gothic Imagination. Cambridge, MA: Harvard University Press.

Horozco, Sebastián de (1896). «Memoria y relación de un extraño caso agora aconteçido y descubierto, de una mala y cruel mujer de la villa de Roa, que es 18 leguas de Valladolid (año 1560)». Relaciones históricas de los siglos XVI y XVII. Madrid: Imprenta de la viuda e hijos de M. Tello, pp. 60-64.

LóPez de ÚbedA, Francisco (1977). La pícara Justina [1605]. Antonio Rey Hazas (ed.). Madrid: Editorial Nacional.

MARCO, Joaquín (1977). Literatura popular en España en los siglos XVIII y XIX (una aproximación a los pliegos de cordel). Madrid: Taurus, vol. 2.

PÉREz, Francisco (1606). Verissima relacion, donde se cuenta la gran crueldad que una muger uso con su marido, y una donzella vezina suya [...] juntamente con un gracioso romance al cabo. Barcelona: [s.e.].

Río PARRA, Elena del (2016). «Morir por partes. Criminografía en relatos de homicidio temprano-modernos». Hispania felix: Revista rumano-española de cultura y civilización de los Siglos de Oro, 7, pp. 213-234. 
Schmid, David (2010). «True Crime». En Charles J. Rzepja y Lee Horsley (eds.), A Companion to Crime Fiction. West Sussex: Wiley-Blackwell, pp. 198-209.

Sото, Francisco (1617). Relación verdadera en la qual se declara como en la ciudad de Murcia un hombre sastre mato a su mujer preñada de siete meses este año de 1617. Porque le quebró una aguja estando cosiendo incitado del demonio, y cómo después se le apareció el mismo demonio en figura de hombre humano, y le llevó a una cueva donde le hizo de vestir sin conocerlo. Dase cuenta en la obra cómo fue descubierto, y el castigo que le fue dado. Barcelona: Bautista Sorita.

Thompson, Stith (1955-1958). Motif-Index of Folk-Literature: A Classification of Narrative Elements in Folktales, Ballads, Myths, Fables, Mediaeval Romances, Exempla, Fabliaux, Jest-Books, and Local Legends, 6 vols. Bloomington: Indiana University Press.

Villegas, Alonso de (1594). Fructus sanctorum. Cuenca: Juan Masselin.

VV. AA. (1862). Cartas de algunos padres de la Compañia de Jesús, II. Memorial histórico español XIV. Madrid: Imprenta Nacional.

VV. AA. (1863). Cartas de algunos padres de la Compañía de Jesús, V. Memorial histórico español XVII. Madrid: Imprenta Nacional.

VV. AA. (1864). Cartas de algunos padres de la Compañia de Jesús, VI. Memorial histórico español XVIII. Madrid: Imprenta Nacional.

VV. AA. (1780). Diccionario de la lengua castellana compuesto por la Real Academia Española, reducido a un tomo para su más fácil uso. Madrid: Joaquín Ibarra.

Recibido: 28/07/2018

Aceptado: 29/08/2018 


\section{(2)}

El CULTO AL EXCESO EN LOS INICIOS DEL IMAGINARIO CRIMINAL EN ESPAÑA

RESUMEN: ¿Cómo representar un asesinato de manera excesiva, para distinguirlo de otros crímenes notables? Este trabajo explora, a través de una serie de casos representativos, la construcción del exceso como categoría criminal, ya de por sí desbordante, tomando prestados recursos de géneros preexistentes. Dentro de un mercado cultural muy particular en el que priman, no solo la cantidad, sino rasgos cualitativos, se examinan asesinatos en serie y en masa, el uso de las cifras, el encadenamiento, y fórmulas y arquetipos folklóricos.

PALABRAS ClAVE: asesinato en serie y en masa, suceso criminal, exceso, cantidad y calidad, sistemas para matar, fórmulas y motivos, patrones narrativos.

\section{THE CULT of EXCESS at the DAWN OF SPAIN's CRIMINAL IMAGINARY}

ABSTRACT: How can a murder be excessively represented to set it apart from other notable crimes? This article explores, through a number of representative cases, the construction of excess as criminal category, one in itself overwhelming, borrowing resources from preexisting genres. Mass and serial murder, the use of numbers, chain structures, and folkloric archetypes and formulae will be examined, within a very particular cultural marketplace filled with not only quantitative but qualitative traits.

KEYWORDS: mass and serial murder, criminal event, excess, quantity and quality, killing systems, formulae and motifs, narrative patterns. 


\section{Edad de Oro. Revista de Filología Hispánica}

ISSN: 0212-0429 - ISSNe: 2605-3314 <https://revistas.uam.es/edadoro/index>

Edad de Oro es uno de los máximos referentes en el área de investigación en Filología Hispánica, especialmente de los siglos XVI y XVII. Goza de un amplio reconocimiento en el ámbito académico internacional. Desde 1982 publica ininterrumpidamente, con una periodicidad anual, colaboraciones científicas de los principales especialistas de diversos centros nacionales y extranjeros. Con un público compuesto esencialmente por investigadores y expertos de todo el mundo, se dirige a cualquier persona interesada en las nuevas corrientes de los estudios humanísticos de su campo.

Dirección:

María Jesús Zamora Calvo

(Univ. Autónoma de Madrid)

Subdirección:

José Antonio Llera Ruiz

(Univ. Autónoma de Madrid)

Secretaría:

Raquel Arias Careaga

(Univ. Autónoma de Madrid)

Consejo de redacción:

Cecilia López-Ridaura

(ENES. Morelia / Univ. Nacional

Autónoma de México)

José Luis Ocasar Ariza

(Univ. Autónoma de Madrid)

Rocío Pérez Gironda

(Univ. Autónoma de Madrid)

Carolina Fernández Cordero

(Iberoamericana-Vervuert)

Admisión de originales:

María Jesús Zamora Calvo

Edad de Oro

Universidad Autónoma de Madrid

Facultad de Filosofía y Letras

Departamento de Filología Española

Campus Cantoblanco

28049 Madrid (España)

Tfno. (+34) 914976886

Correo-e: mariajesus.zamora@uam.es

Distribución, suscripción y venta:

Servicio de Publicaciones de la UAM

Universidad Autónoma de Madrid

28049 Madrid (España)
Intercambio de publicaciones:

Biblioteca de Humanidades

Universidad Autónoma de Madrid

28049 Madrid (España)

Comité científico:

Carlos Alvar (Université de Gèneve)

Ignacio Arellano (Univ. de Navarra)

Alberto Blecua

(Univ. Autónoma de Barcelona)

Jean Canavaggio

(Université Paris Nanterre)

Aurora Egido (Univ. de Zaragoza)

Víctor García de la Concha (RAE)

Luciano García Lorenzo (CSIC)

Joaquín González Cuenca

(Univ. de Castilla la Mancha)

Agustín de la Granja López

(Univ. de Granada)

Begoña López Bueno (Univ. de Sevilla)

Michel Moner

(Universitè Toulouse - Jean Jaurès)

Joan Oleza (Univ. de Valencia)

Alfonso Rey

(Univ. de Santiago de Compostela)

Lina Rodríguez Cacho

(Univ. de Salamanca)

Leonardo Romero Tobar

(Univ. de Zaragoza)

Aldo Ruffinatto

(Università degli Studi di Torino)

Lía Schwartz

(City University of New York)

Han colaborado en este volumen:

Departamento de Filología Española

(UAM)

Facultad de Filosofía y Letras (UAM)

Edad de Oro se recoge en las siguientes bases de datos y directorios: DICE; HLAS; MLA International Bibliography; PIO; ISOC-CSIC; DIALNET; SUMARIS CBUC; ULRICH'S.

Se encuentra evaluada en: SCOPUS: Q2; SCImago: SJR 2017 0.11, H Index 4; ERIH Plus: category A; CIRC: categoría C; RESH: 0.162; MIAR: ICDS 2017 10.0; CARHUS Plus+: C; LATINDEX. 


\section{EDAD DE ORO}

Revista de Filología Hispánica XXXVII

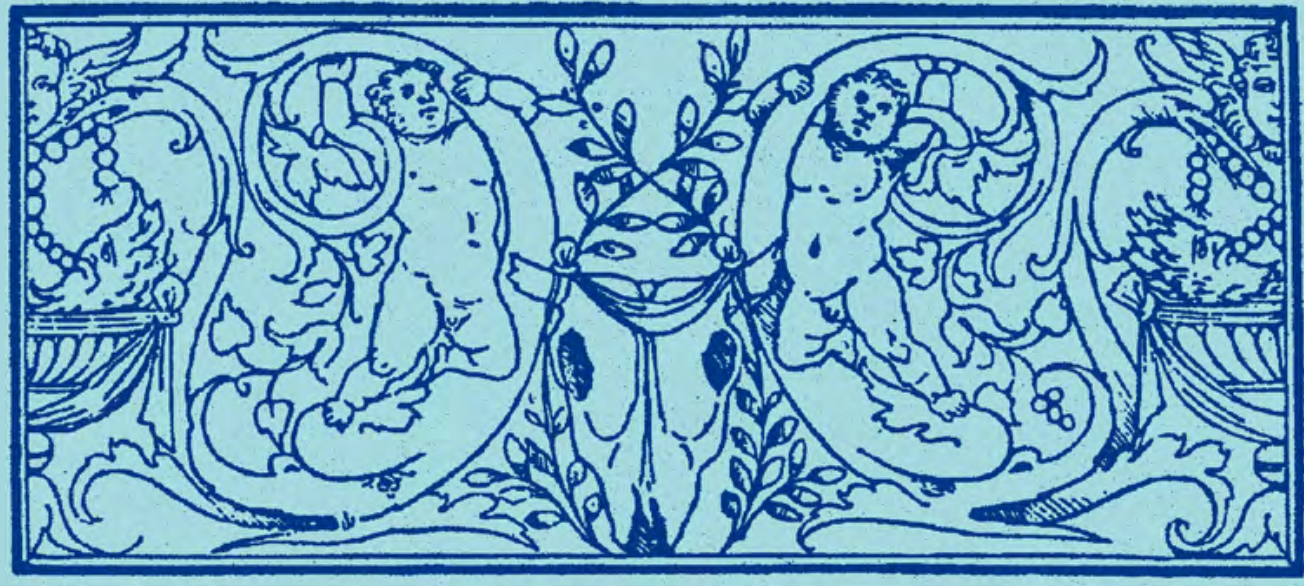

\section{DEPARTAMENTO DE FILOLOGÍA ESPAÑOLA}

EDICIONES DE LA UNIVERSIDAD AUTÓNOMA DE MADRID 